\title{
Reseña del Libro "Derecho Financiero y Derecho Tributario: ensayos en honor al profesor José Vi- cente Troya Jaramillo"
}

Book Review "Financial Law and Tax Law: essays in honor of Professor José Vicente Troya Jaramillo"

Mgr. Edwin Germánico Lara Benavides

Investigador jurídico independiente

Artículo Original (Recensión)

RFJ, No. 6, 2019, pp. 439-449, ISSN 2588-0837

Recensión de Albán Zambonino, Marco, Derecho financiero y derecho tributario ensayos en honor del profesor José Vicente Troya Jaramillo, Instituto Ecuatoriano de Derecho Tributario, Quito, 2017, 608 pp. ISBN 978-9942-28-289-7

Review of Albán Zambonino, Marco, Derecho financiero y derecho tributario ensayos en honor del profesor José Vicente Troya Jaramillo, Instituto Ecuatoriano de Derecho Tributario, Quito, 2017, 608 pp. ISBN 978-994228-289-7

PALABRAS CLAVE: Garantías del contribuyente, recursos por omisión, actividad financiera del estado, principio de equivalencia, derecho presupuestario.

KEY WORDS: taxpayer guarantees, default resources, state financial activity, equivalence principle, budget law.

\section{INTRODUCCIÓN}

Las obras magistrales siempre deben ser enunciadas y dadas a conocer para que toda la comunidad pueda, con algunas referencias y reflexiones, acceder y aprovechar el conocimiento escondido en obras como la que voy a reseñar en el presente artículo. 
Al ver la portada y una parte del título, me doy cuenta de que se tratan de ensayos en honor al profesor José Vicente Troya Jaramillo, me pregunté: ¿̇e tratarán solo de dedicatorias, o se tratará también de discursos y artículos inéditos de quienes lo admiraban? Pues bien, ahí está el detalle, la magna obra que ha sido escrita por discípulos, tanto coterráneos como extranjeros, debe ser difundida a toda la comunidad de Abogados en general donde, además de enterarse de la espectacular carrera del señor Doctor José Vicente Troya Jaramillo, orgullosamente ecuatoriano, y de lo admirado que ha sido y sigue siendo tanto en el Ecuador como en la comunidad de Tributaristas de todo el mundo podrán, adicionalmente, alimentar sus conocimientos con temas de altísimo interés y complemento para nuestra área.

\section{GENERALIDADES DE LA OBRA}

A continuación, comentaré para así, dejar abierta la puerta a profundizar temas interesantes alrededor del Derecho Tributario, Derecho Financiero, Derecho presupuestal, Derecho Financiero Constitucional, Derecho del Gasto Público, Derecho Constitucional Tributario entre otros. La obra mencionada contiene, básicamente, 4 secciones (distribuidas de distinta manera en el libro): primera parte que describe la semblanza del Dr. José Vicente Troya; un conjunto de artículos internacionales; un segundo conjunto de artículos nacionales; y un tercer conjunto de homenajes.

La semblanza es descrita por la autora Carmen Amalia Simone, quien colaboró directamente por 12 años con el Dr. Troya. Ella destaca el importante sentido de la vida del profesor, así como su enorme capacidad como profesional, maestro y precursor del Derecho Tributario en el Ecuador.

El Dr. José Vicente Troya es de origen Guarandeño, nacido el 15 de septiembre de 1933 y descendiente de Abogados, por lo que el derecho lo llevaba en la sangre. Fue Quito su ciudad de residencia donde creció y formó su familia llegando hasta tener tres bisnietos.

Sus estudios los realizó en el colegio San Gabriel, para luego cursar estudios universitarios en la Pontificia Universidad Católica del Ecuador mostrando, desde ahí, su dedicación al graduarse con honores de Licenciado en Ciencias Sociales, Abogado y Doctor en Jurisprudencia. 
Dentro del recorrido por esta magnífica descripción la autora, detalladamente, describe detalladamente las varias funciones y cargos que ha tenido a lo largo de su vida profesional y los honores y reconocimientos internacionales; así como sus logros académicos y estudios de postgrado para concluir con, broche de oro, el amplio repertorio de obras y artículos que el profesor Dr. José Vicente Troya Jaramillo dejó como legado para, incluso luego de su penosa partida un año atrás, seguir compartiendo conocimientos al haber dejado artículos sin publicar, dos de ellos presentes en la obra en su memoria.

Dentro de las obras que deja el profesor Dr. José Vicente Troya Jaramillo, se destacan dos artículos inéditos:

Garantías del Contribuyente ante la Administración Tributaria, producto de una ponencia a la cual fue invitado para las XXVI jornadas Latinoamericanas de Derecho Tributario, realizadas en el mes de septiembre del mismo año en Compostela - España. El desarrollo de la ponencia fue autorizado por la familia para que sea parte del libro ahora reseñado, cuyo prólogo y análisis lo desarrolla el Dr Marco Albán Zambonino. En dicho ensayo, usted, estimado lector, podrá encontrar que el camino para que el contribuyente pueda hacer valer sus derechos está completamente marcado siempre y cuando tengamos el conocimiento o el abogado que sepa hacer valer nuestros derechos, pues es importante mencionar que, además de las instancias nacionales, el contribuyente puede ir a instancias internacionales como el Tribunal de Justicia de la Comunidad Andina que, incluso en varias sentencias en materia tributaria, ha intervenido basado en las decisiones de la Comisión de la Comunidad Andina, como son: la Decisión 40, expedida el 28 de enero de 1975; la Decisión 578 del 4 de mayo del 2004; la Decisión 292, emitida por la Comisión del acuerdo de Cartagena de 21 de marzo de 1991, entre otras.

Los recursos, actuaciones y acciones que los contribuyentes pueden proponer ante el Tribunal de Justicia de la Comunidad Andina son:

a) La interpretación prejudicial, dentro de algunas causas mencionadas por el Dr. Albán están: 188-IP-2005; 190-IP-2006; 93-IP2008;124-IP-2010; 125-IP-2010; IP-37-2011; 63-IP-2011.

"Los casos precedentes son demostrativos de cómo los contribuyentes personas naturales o jurídicas, gracias a las interpretaciones emitidas por el T.J.C.A., puede hacer valer sus derechos ante las adminis- 
traciones tributarias, constituyéndose este instrumento en garantía de los contribuyentes".

b) La acción por incumplimiento, destinada a demostrar el incumplimiento de los países miembros de los compromisos comunitarios y de la normativa comunitaria según el artículo 4 del tratado de creación de la T.J.C.A., "los Países Miembros están obligados a adoptar las medidas que sean necesarias para asegurar el cumplimiento de las normas que conforman el ordenamiento jurídico de la Comunidad Andina. Además, se comprometen, así mismo, a no adoptar ni emplear medida alguna que sea contraria a dichas normas o que algún modo obstaculicen su aplicación”. (Albán, 2017) Dentro de algunas acciones de incumplimiento en materia tributaria presentadas al T.J.C.A., tenemos 53-AI-2000.

c) La acción de nulidad, los contribuyentes afectados pueden presentar recursos de nulidad, pero, obviamente, estas acciones pueden ser incoadas por los Países Miembros, el Consejo Andino de Ministros Relaciones Exteriores, La Comisión de la Comunidad Andina y la Secretaría General. Dentro de las causas presentadas hasta la fecha de la ponencia están: proceso 79-AN-2000; 2-AN-2007.

d) Recursos por Omisión, este recurso, que no registra casos que se haya ejercido esta situación a la fecha de la ponencia, puede ejecutarse por los contribuyentes cuando se compruebe que las decisiones de la CAN afectan los derechos subjetivos o sus intereses legítimos.

Según las resoluciones de la Secretaría General, de forma alternativa, podemos presentar recursos y acciones ante la Secretaría General de la CAN y, lógicamente, en forma concomitante se podrán ver cumplidos nuestros derechos y garantías. El Dr. Marco Albán menciona algunos casos relevantes como: Resolución 760 de la Secretaría General del 29 de agosto de 2003; Resolución 898 de la Secretaria General del 4 de febrero de 2005; Resolución 1039 de la Secretaría General del 21 de julio de 2006; Resolución 1254 de la Secretaría General de 12 de agosto de 2009.

Para conocimiento más amplio sobre los casos planteados, el lector puede recurrir a la obra en honor al profesor Dr. José Vicente Troya Jaramillo, en donde, claramente, nos abre el horizonte de las garantías del contribuyente incluso en instancias internacionales. 
Es importante, también, destacar que dentro de este aspecto el lector puede investigar a fondo varios principios que garantizan los derechos del contribuyente, entre ellos, el principio de supranacionalidad.

El segundo artículo inédito del profesor Dr. José Vicente Troya a destacar, La actividad financiera del Estado y las ciencias que tratan de ella, cuyo prólogo cuenta con la pluma de la Dra. Eddy De La Guerra Zúñiga, fue escrito en 1990 y, debido a su trascendencia, ha sido editado por el profesor en varias ocasiones. Su última versión se encuentra en las páginas del libro en honor al profesor Dr. José Vicente Troya. En este ensayo tenemos subtemas como el tratar de describir la actividad financiera pública y su diferencia con la actividad económica, considerando la posición de varios autores y expertos en la materia, así como Giannini, Banacloche, Jiménez, Amorós, Martín, Villegas, entre otros. Considerando también aspectos como describir la naturaleza de la actividad financiera, consensuando, según varios autores, que la actividad financiera tiene relación con aspectos económico, políticos, sociológicos y que no soluciona los problemas de las necesidades de la política. Es decir, es un conjunto de ramas que, en ciertos casos, están dentro de toda una madeja de conceptos, pero que es importante desmenuzarla para entender las bases de diferentes criterios. Para el lector y Abogado Tributarista es importante tener la concepción y el conocimiento de estos términos, que no solo atañen a los economistas, ni financieros, ni sociólogos, ni politólogos ya que en todo estará presente el Derecho con diferentes ámbitos de aplicación.

Así, también, se hace una amplia explicación de los conceptos de ciencias que regulan, desde diferentes puntos de vista, a la actividad financiera, citando desde autores de principios de finanzas hasta los más completos conceptos y definiciones, haciendo alusión a autores como Grizzioti, entre los principales. Pero de toda la amplia investigación del profesor Dr. José Vicente Troya, los términos más recurrentes que se encuentran alrededor de la Actividad Financiera son: Ciencia de la Hacienda, Ciencia Fiscal, Ciencia de las Finanzas Públicas, Finanzas Públicas, Economía Financiera, Política Financiera, Derecho Financiero, Derecho Fiscal, Derecho Tributario, Derecho Impositivo, Técnica Impositiva, Administración Fiscal, Administración Financiera, Derecho Presupuestario, Legislación Fiscal. Dentro de esta cantidad de términos es importante señalar que existen semejanzas y relaciones entre uno y otro, por lo tanto, el profesor en su artículo escoge, de manera acertada, las que considera aclaran el panorama: a) La Ciencia de las Finanzas Públicas, la Economía Financiera, la Política 
Financiera; b) el Derecho Financiero; c) El Derecho Tributario; y d) La técnica impositiva. Todas estas descritas y comparadas con diferentes autores y ampliamente explicadas para que el lector pueda ampliar y profundizar sus conocimientos, aclarando conceptos relacionados con la actividad financiera, sobre todo en lo que concierne a lo que comúnmente se denomina La Ccosa Pública.

Adicionalmente, la obra tiene un acápite de artículos internacionales escritos por discípulos del profesor Dr. José Vicente Troya Jaramillo, lo que genera una ansiedad abrumadora sobre la investigación dentro de la rama del Derecho y más aún a quienes nos priva el Derecho Tributario, sabiendo que hay un camino recorrido y que los límites no existen, pues en palabras de la misma Dra. Eddy De La Guerra, el agregado de las finanzas públicas al derecho tributario es un común denominador en ciertos profesionales del derecho y más a los apegados al tributario.

A continuación, mencionaré, de manera rápida, los artículos para que ustedes, los lectores, puedan acercarse a la obra y evaluar la importancia del libro en honor al profesor Dr. José Vicente Troya Jaramillo.

El principio de equivalencia. - Rubén O. Asorey, jurista reconocido a nivel nacional, se siente muy complacido de escribir unas pocas letras en homenaje al incólume José Vicente Troya Jaramillo. En el contexto del principio de equivalencia, hace un magnifico análisis sobre lo que significa este principio entre lo que el estado recauda como tributo y el servicio que presta al usuario(llámese ciudadano), es decir, el valor que se paga por un tributo, tasa o contribución, debe tener su correlación con el servicio recibido, considerando incluso varios otros principios como son el de solidaridad y capacidad contributiva, ya que los que más pagan deben cubrir parte de los que menos pagan, terminando incluso en un análisis de la carga probatoria para el estado en el aspecto de la equivalencia, pues al impugnar una deuda dentro del principio de equivalencia, no le queda más a la administración poder demostrar que el servicio se ha prestado.

Los principios de equilibrio y anualidad en materia presupuestaria, escrito por José Osvaldo Casás, argentino galardonado por sus espectaculares obras, en donde se pone de manifiesto la importancia del equilibrio dentro del contexto del presupuesto general de los estados, considerando al equilibrio como la equidad entre los ingresos y los gastos, haciendo notar que existe un déficit, así como un superávit. 
Explica de manera clara la importancia de la actividad del estado dentro de la economía de los países. Este puede ser desde un estado austero, que simplemente tiene pocos tributos que recaudar para cubrir la poca actividad de austeridad que se maneja, así como también puede ser un estado grande con alta demanda de recursos económicos, mismos de los cuales una parte son los tributos, es decir, a más gastos, más tributos. Adicionalmente, se explica de manera clara la intensa lucha de los gobiernos por tratar de tener dicho equilibrio, pues esta temática, unida a la economía y a las finanzas públicas, se vuelve un tema amplio y complejo. Sin embargo, en la obra en honor al profesor Dr. José Vicente Troya, el lector encontrará una amplia explicación sobre el equilibrio. Así, también, al hablar de la anualidad, esta tiene que ver con la periodicidad que se plantean los presupuestos estatales, haciendo una descripción clara, precisa y amplia con una espectacular comparación de autores, conceptos y aplicaciones que, en algunos casos, han llegado a ser plurianuales, todo esto con el único afán de que el conocimiento sea distribuido a todo el que lo quiera tener. El equilibrio y la periodicidad son una problemática a nivel mundial, pues no siempre es fácil establecer anualmente un presupuesto que, adicionalmente, esté acompañado de legislación que autorice su ejecución; así mismo, dentro de las citas, podrá usted conocer que, incluso, la legislación ha alcanzado hasta la regulación del endeudamiento de países, como se toma el caso argentino en el fascinante artículo del Dr. José Osvaldo Casás.

Nuevos Horizontes Constitucionales del Derecho Presupuestario en el Mundo Global, escrito por Horacio Corti, se hace una amplia explicación de la obra del profesor Dr. José Vicente Troya Jaramillo, "El derecho del gasto público, Especial referencia a los derechos económicos, sociales y culturales". Habiendo recibido la magistral obra con dedicatoria, y sintiendo que son parte de una escuela latinoamericana de derecho financiero y presupuestario, el autor rinde homenaje a su compañero de investigaciones, pues dentro del artículo hace referencia y explicación a lo que tiene que ver con el presupuesto y la relación directa con la constitución, pues el presupuesto es tan antiguo como el estado y requiere, de alguna manera, tener su base legal en la constitución, así como una legislación del control del gasto y de la deuda. También se habla de una Constitución Financiera, haciendo una amplia explicación histórica del Derecho Presupuestario y su relación con la base misma de la Constitución, por lo que busca justificar que la Constitución debería contener los parámetros para la legislación del presupuesto. Así mismo, el autor hace un recorrido por legislaciones 
de varios países, haciéndonos conocer, de manera expedita, lo que los libros y autores cuentan.

El Derecho Aduanero y su relación con el Derecho Tributario. Germán Pardo Carrero, allegado cercano del profesor Dr. José Vicente Troya, que en su artículo destaca la importancia de analizar en qué lugar se encuentra hoy en día el Derecho Aduanero, que siempre fue parte del Derecho Tributario. Busca enmarcar dentro de este ensayo la diferencia amplia entre las dos ramas del derecho, ya que el Derecho Tributario se dedica al estudio de los tributos clasificados como tales en impuestos, tasas y contribuciones, mientras que el Derecho Aduanero ha ido tomando amplia independencia al dedicarse al comercio exterior y el debido control del mismo. Considerando que la globalización es un hecho que no tiene retorno y que ahora la importancia es el control de las fronteras frente al creciente contrabando y los convenios y tratados entre los países. Finalmente, cabe destacar que existe una plena relación entre ambos derechos que es estricta y estrechamente dada por los tributos.

Dentro de la IV sección se han hecho presentes varios de sus discípulos ecuatorianos, realizando artículos de interesante temática. Resulta menester, al menos, poner en consideración los nombres de tan destacados profesionales

Ensayos, reflexiones y reseñas sobre los escritos del Dr José Vicente Troya, son obras de muchos autores afines, estudiantes y varias personalidades del Ecuador que se pueden descubrir en el libro en su homenaje. Estos textos refieren a temas importantes como la consulta tributaria en el Ecuador, La argumentación y fundamentación jurídica, derecho constitucional, finanzas públicas, la Plusvalía, los Principios Constitucionales y Tributarios, entre otros. Dichos temas son los acápites de esta obra.

Creo que los editores se esforzaron al crear, con tanta amplitud, una obra que, si bien no es la total de los temas tributarios, al menos topa los principales de uso diario para los ecuatorianos.

La Tributación de los Gobiernos Locales. En este cóctel de temáticas que componen el interesante mundo del Derecho Tributario, no podía faltar la presencia del Dr. José Suing, quien se ha destacado por su especialidad sobre el Derecho Tributario Municipal. Siendo un gran referente, explica en su ensayo una síntesis bastante acertada a los 
Gobiernos Autónomos Descentralizados y su participación como sujetos pasivos. En este ensayo resulta importante destacar la labor del Dr. Suing, ya que pone en conocimiento del lector la participación del Dr. José Vicente Troya en la Constitución del 98, para que se considere a los gobiernos locales en el cuerpo normativo y de esta manera se aplique y enuncie el principio de Reserva de Ley.

La Casación Tributaria en el Ecuador, abordado por la Dra. Maritza Tatiana Pérez Valencia, connotada Tributarista del Ecuador, alude a todo un repertorio histórico del Recurso de casación respecto de una ponencia realizada por el Dr. José Vicente Troya en el año 2013, en el seminario "Casación y Argumentación Jurídica en Materia Tributaria", realizado en las instalaciones de la Universidad Andina Simón Bolívar. En aquella ocasión, como en todas, el profesor Dr. José Vicente había realizado una ponencia de altísima calidad sobre la casación, lo que motivó a la Dra. Tatiana Pérez a estructurar este tema dentro del merecido homenaje al distinguido profesor, introducirse en tan apasionante tema y encontrar los recovecos más importantes de este recurso es lo que, sin duda, consigue la autora del artículo dentro de los párrafos desarrollados.

Invito a usted, estimada y estimado colega, para que se involucre en esta magnífica obra que se ha creado con un esfuerzo del Instituto Ecuatoriano de Derecho Tributario en homenaje al Dr. José Vicente Troya, no se arrepentirá.

\section{CONCLUSIONES}

Es importante conocer que tenemos diferentes instancias para que prevalezcan los derechos de nosotros como contribuyentes, así como saber también que podemos ser asesores o abogados que hagamos prevalecer los derechos de nuestros clientes en instancias internacionales. El Derecho Tributario es independiente, no hay ninguna duda de ello, sin embargo, es necesario incluir ciertos conceptos y términos que, si bien pueden ser para nosotros similares, los estudiosos han aclarado en varias obras el significado y el alcance de toda esta terminología explicada en el artículo del Dr. José Vicente Troya.

Dentro de los principios de equivalencia mencionados, es importante destacar que, en especial, dentro de lo que es contribución especial de mejoras o prestación de servicios o precio servicio público, se 
puede impugnar el pago o la deuda donde la carga de la prueba será para el sujeto activo. Una grave problemática de los países es llegar al perfecto equilibrio de la economía, considerando sus ciclos productivos y de recesión. Hasta ahora al hombre se le ha hecho muy difícil este manejo y basta con ver algunos resultados como la pobreza en el mundo y el abuso de los gobiernos de los fondos públicos de diferente forma; por lo que hablar de equidad y anualidad (por la periodicidad) es importante para los Abogados, quienes también deben incrementar estos conocimientos.

El presupuesto, las finanzas, la actividad financiera, la economía, la política, los ingresos y gastos corrientes, todo un mundo de información que para seguir profundizando las fuentes del Derecho Tributario podemos investigar e ir desarrollando conocimientos. Una fascinante comprensión sobre las diferencias y campos de aplicación del Derecho Tributario y el Derecho Aduanero es la que en esta obra se ha plasmado, es importante ir definiendo todo lo que no es y lo que se relaciona las ramas del Derecho enunciado. Para usted, señor lector, será de mucho interés insertarse en el mundo del Derecho Aduanero como rama independiente y su relación directa con el Derecho Tributario.

Tanto en el ámbito local como internacional, es indiscutible el importante aporte que el Dr. José Vicente Troya ha realizado para la rama del Derecho Tributario. Este merecido homenaje nos deja ver que estaba rodeado de profesionales de altísimo nivel y que sembró, en muchos de sus alumnos y colaboradores, esa cápsula que lleva a contagiar del ansia del saber que hoy, magníficamente, han plasmado sus allegados, colaboradores, alumnos y más. Todos con sentidas palabras de cariño, respeto y admiración hacia el homenajeado.

\section{REFERENCIAS BIBLIOGRÁFICAS}

Albán M. (2017). Derecho Financiero y Derecho Tributario: ensayos en honor al profesor José Vicente Troya Jaramillo, Quito: IEDT.

Jarach, D. (1957). Curso Superior de derecho tributario, 2da. Edición. T.I. Buenos Aires: Liceo Cima. 
Troya, J. V. (2014). El derecho del Gasto público. Especial referencia a los derechos económicos, sociales y culturales, Bogotá: Temis.

Recibido: 26/07/2019

Aprobado: 17/11/2019

Edwin Germánico Lara: Investigador jurídico independiente

Correo electrónico: edwin_lara_b@hotmail.com 